\title{
Efeitos da Salmonella Enteritidis experimentalmente inoculada na saúde gastrintestinal de perus
}

\author{
Carla Yoko Tanikawa de Andrade ${ }^{1}$, Maria Auxiliadora Andrade ${ }^{1}$, Marcos Barcellos Café ${ }^{1}$, \\ José Henrique Stringhini ${ }^{1}$, Anderson Mori ${ }^{1}$, Dunya Mara Cardoso Moraes ${ }^{1}$, Juliana Bonifácio \\ Alcântara $^{1}$, Hérika Xavier Costa ${ }^{1}$
}

${ }^{1}$ Universidade Federal de Góias.

RESUMO - Avaliaram-se os efeitos de Salmonella Enteritidis sobre a colonização e o desenvolvimento do trato intestinal, a conversão alimentar e o ganho de peso em perus. Um total de 135 perus de corte de 1 dia foi distribuído em três tratamentos: controle; perus oriundos de ovos inoculados com Salmonella Enteritidis via casca e perus desafiados com água de bebida com Salmonella Enteritidis. Aos 10, 20 e 28 dias, avaliaram-se as variáveis de desempenho e coletaram-se amostras para avaliação bacteriana, biometria e histomorfometria. Realizaram-se também, nos dias 1, 15 e 28 de idade, coletas de mecônio/excretas de todas as aves. A colonização intestinal aumentou durante a fase inicial quando Salmonella foi inoculada via casca. O intestino apresentou maior peso ao $1^{\circ}, 10^{\circ}$ e $28^{\circ}$ dias quando Salmonella esteve presente, sem diferença no comprimento. Salmonella Enteritidis foi capaz de colonizar o trato intestinal, estabelecer infecção, reduzir o desempenho das aves e modificar as estruturas celulares do intestino. A contaminação da casca do ovo antes da incubação propiciou a ocorrência de infecções ao nascimento, e a frequência de isolamento de Salmonella Enteritidis persistiu até 28 dias de idade. A inoculação de Salmonella pela água de bebida gerou aves infectadas, porém com menor nível de infecção com o avançar da idade. O desempenho de aves inoculadas com Salmonella Enteritidis é menor e isso confirma potenciais prejuízos para a produção avícola.

Palavras-chave: colonização intestinal, histomorfometria, Meleagridis gallopavo, salmonelose

\section{Effects of experimentally inoculated Salmonella Enteritidis on the gastrointestinal health of turkeys}

\begin{abstract}
The effects of Salmonella Enteritidis on the colonization and development of the intestinal tract, feed conversion and weight gain were evaluated. A total of 135 day old turkeys were assigned to three treatments: control; turkeys from eggs inoculated with Salmonella Enteritidis via shell and turkeys challenged with drinking water with Salmonella Enteritidis. At 10, 20 and 28 days, the performance variables were evaluated and samples were collected to perform bacterial assessment, biometrics and histomorphometry. On days one, 15 and 28, samples of meconium/excreta were collected from all birds. The intestinal colonization increased during the initial phase when Salmonella was inoculated via eggshell. The intestine showed greater weight on the first, tenth and 28th days when Salmonella was present, with no differences regarding the intestine length. Salmonella Enteritidis was able to colonize the intestinal tract, establish infection, reduce bird performance and modify the cellular structures of the intestine. Contamination of the eggshell before hatching generated birds susceptible to infection at birth and the frequency of isolation of Salmonella Enteritidis persisted until 28 days of age. Salmonella inoculation by drinking water generated infected birds, but with less recovery of the pathogen with age increase. Inoculated birds showed inferior performance, confirming the potential damage to poultry production.
\end{abstract}

Key Words: intestinal colonization, histomorphometry, Meleagridis gallopavo, salmonelose

\section{Introdução}

Bactérias do gênero Salmonella estão amplamente distribuídas na natureza em diferentes espécies animais e, em perus, podem resultar em severas perdas econômicas, devido aos altos custos com erradicação e medidas de controle (Krüger et al., 2008). No Brasil, infecções paratíficas nesta espécie são observadas ocasionalmente e não têm sido associadas a doença clínica ou mortalidade (Back, 2008). De acordo com Back (2002), essas infecções inaparentes são mais preocupantes do ponto de vista da saúde pública, uma vez que as aves agem como reservatórios e introduzem Salmonella sp. na cadeia alimentar do homem.

O intestino é uma mistura complexa de diferentes populações bacterianas. A diversidade de substratos em cada segmento intestinal permite a existência das mais 
variadas populações bacterianas, as quais, em combinação com vários fatores, podem resultar em processo infeccioso. Estudos de inoculações experimentais com enteropatógenos podem contribuir para melhor compreensão dos fatores envolvidos em infecções entéricas assintomáticas, como a habilidade de colonizar o intestino, determinar injúrias nas mucosas intestinais e ainda comprometer a digestão e absorção de nutrientes (Dhillon et al., 2001; Andrade et al., 2009).

Em perus, o desenvolvimento intestinal imediatamente após a eclosão e até duas semanas de vida tem sido descrito na literatura (Uni et al., 1999; Noy et al., 2001; Applegate et al., 2005), entretanto raramente relacionado à infecção por Salmonella sp. (Potturi et al., 2005).

Diante da comprovada circulação de Salmonella Enteritidis na avicultura goiana (Rocha et al., 2003) e no Brasil (Silva \& Duarte, 2002) e considerando o crescimento da produção de perus em Goiás, realizou-se este trabalho com o objetivo de avaliar os efeitos da Salmonella Enteritidis na colonização do trato intestinal, no desenvolvimento de alterações histomorfométricas e no desempenho de perus comerciais.

\section{Material e Métodos}

Foram utilizados 135 perus de corte da linhagem British United Turkeys distribuídos em delineamento inteiramente casualizado, com três tratamentos, nove repetições e cinco unidades experimentais por parcela: controle - perus oriundos de ovos inoculados na casca com solução salina a $0,85 \%$ estéril; perus oriundos de ovos desafiados com 4,2 $210^{4}$ unidades formadoras de colônias (ufc)/mL de Salmonella Enteritidis na casca no primeiro dia de incubação; perus com 1 dia de vida desafiados com $4,2 \times 10^{4}$ ufc/mL de Salmonella Enteritidis por 24 horas.

As aves foram alojadas em baterias aquecidas, equipadas com comedouros e bebedouros. Os grupos controles foram alojados em sala separada dos grupos inoculados como forma de evitar a contaminação entre grupos. A temperatura de conforto térmico compatível com a idade foi mantida por meio de lâmpadas.

Água e ração foram disponibilizadas à vontade. A ração continha ingredientes de origem vegetal, sem antibióticos ou anticoccidiano, e foi elaborada segundo exigências nutricionais da linhagem British United Turkey Big 9 (BUT, 2006a).

As aves foram identificadas e pesadas individualmente com 1, 10, 20 e 28 dias de vida, assim como as rações e as sobras. O consumo de ração foi obtido pela diferença entre os valores de ração oferecida no início e as sobras, corrigidos pela mortalidade. O índice de conversão alimentar foi calculado pela relação entre o consumo de ração e o ganho de peso corrigido pelo peso das aves mortas.

Com 1, 10, 20 e 28 dias, após pesagem, cinco aves de cada tratamento foram submetidas a jejum alimentar por 6 a 8 horas, sendo posteriormente sacrificadas por deslocamento cervical e necropsiadas. Os intestinos delgado e grosso foram removidos, pesados (g) e medidos (cm) para biometria, realizada considerando o peso relativo do intestino $\times 100$, dividido pelo peso vivo, expresso em $\mathrm{g} / 100 \mathrm{~g}$ de peso vivo.

Paralelamente, nos mesmos animais, foram coletadas amostras de intestino, (mecônio/conteúdo cecal e suabe cloacal) para pesquisa de Salmonella. Também foram coletados fragmentos de aproximadamente $3,0 \mathrm{~cm}$ de comprimento da porção inicial do duodeno, do jejuno a $2 \mathrm{~cm}$ acima do divertículo de Meckel e do íleo próximo da junção ileocecal para realização da histomorfometria e pesquisa de Salmonella. Os fragmentos de intestino foram fixados em formol salino tamponado a $10 \%$ por 24 horas e recortados em 5,0 mm de diâmetro para acondicionamento em cassetes e processadas de acordo com a metodologia convencional de Luna (1968) para inclusão em parafina. Os cortes histológicos foram corados com hematoxilina-eosina (HE).

As preparações foram submetidas aos índices morfométricos com o auxílio do software Axion Vision 3.0. As imagens das lâminas foram digitalizadas do microscópio óptico de campo claro para o computador, por meio da câmera de vídeo digital, e para a placa de captura. Em seguida, foi realizada a histometria quantificada em micra (Uni et al., 1998).

Com 1, 15 e 28 dias de idade, foram coletadas amostras de mecônio e/ou excretas de todas as aves por compressão da região dorso-ventral da cloaca ou por suabe cloacal para pesquisa do patógeno inoculado.

A pesquisa de Salmonella foi realizada de acordo com o proposto em GPL (1997) e Brasil (2003). Isolados que apresentaram reações bioquímicas compatíveis com Salmonella foram submetidos ao teste sorológico com antissoros polivalentes somáticos e as amostras positivas foram remetidas à Fundação Oswaldo Cruz (Fiocruz) em meio ágar nutriente para confirmação do sorovar recuperado.

Para as análises das variáveis quantitativas, foi utilizado o programa SAEG (Sistema de Análise Estatística e Genética, versão 8.0) com análise de variância e as médias comparadas pelo teste Tukey com a igual a 5\% (Euclides, 1983). O quiquadrado $\left(c^{2}\right)$ foi empregado para avaliar a frequência de perus infectados entre as duas vias de inoculação pela Salmonella Enteritidis (Sampaio, 2002). 


\section{Resultados e Discussão}

O mecônio e as excretas das aves que receberam salina $0,85 \%$ foram bacteriologicamente negativos em todas as idades.

Observou-se que, ao nascimento, 10,53\% (6/57) dos perus oriundos de ovos inoculados via casca foram positivos para o patógeno. Esse número aumentou para $38,9 \%$ (14/36) aos 15 dias, atingindo 40,7\% (11/27) aos 28 dias do experimento (Tabela 1). A via de inoculação na casca ampliou a colonização intestinal por Salmonella Enteritidis até o $28^{\circ}$ dia. Provavelmente os perus se infectaram nas baterias após o nascimento, pelo contato indireto com as excretas contaminadas. Esses achados também foram observados em infecções cruzadas de frangos de corte durante o crescimento de 1 a 7 dias de idade (Bailey et al., 1994).

Pela análise das excretas, notou-se ainda infecção pelo patógeno em 26,9\% (7/26) das aves aos 15 dias e 16,7\% (3/18) aos 28 dias. Portanto, houve redução na taxa de aves infectadas, embora a via de inoculação não tenha influenciado ( $\mathrm{P}>0,05 \%$ ) a excreção fecal do patógeno aos 15 e 28 dias. Em estudo semelhante, realizado por Rostagno et al. (2006), 12,3\% dos conteúdos cloacais foram positivos para o patógeno. Por outro lado, Charles et al. (1994) não isolaram Salmonella Enteritidis de amostras de suabe cloacal no primeiro dia após desafio, apesar de alta taxa de isolamento ser mantida nas quatro semanas seguintes $(60,67,56$ e $44 \%$, respectivamente). Perus recém-eclodidos são mais susceptíveis à colonização por Salmonella que aves mais velhas, devido à imaturidade do trato gastrointestinal e da instabilidade da microbiota. A estabilização da microbiota intestinal no intestino delgado demora aproximadamente duas semanas após a eclosão, enquanto no ceco demora mais de quatro semanas (Hoover et al., 1997). Com isso, pode-se aventar a hipótese de que a estabilização da microbiota intestinal pode estar relacionada ao desenvolvimento do sistema imunológico. Ao inocular o patógeno no primeiro dia de idade, Salmonella Enteritidis encontraria respostas imunes sistêmica e local formadas (Berthelot-
Hérault et al., 2003), tornando o organismo mais adverso à colonização intestinal que na inoculação in ovo.

Neste estudo, dos 28 conteúdos de cecos analisados, 14 (50\%) foram positivos para Salmonella Enteritidis (Tabela 2).

Salmonella Enteritidis foi recuperada do conteúdo cecal coletados de perus aparentemente saudáveis com 1 , 10, 20 e 28 dias de idade. Nas amostras de ceco analisadas, 43,75 e 58,33\% foram bacteriologicamente positivas nas inoculações via casca e via água de bebida, respectivamente. Paralelamente, em 41,67 e 50,00\% das amostras de suabes cloacal, foi realizado o isolamento do patógeno.

Cox et al. (2001) desafiaram perus de três dias de idade com $10^{4}$ ufc de Salmonella Typhimurium e observaram a presença desse patógeno em $46,7 \%$ dos cecos analisados às seis semanas de idade.

A via de inoculação não influenciou $(\mathrm{P}>0,05)$ o comprimento do intestino de perus com 1, 10, 20 e 28 dias de idade (Tabela 3). No entanto, quando se analisou o peso relativo do intestino ( $\mathrm{g} / 100 \mathrm{~g}$ de peso vivo), houve diferença $(\mathrm{P}<0,05)$ no $1 \stackrel{\mathrm{o}}{ }, 10^{\mathrm{o}}$ e $28^{\circ}$ dias. No $1 \underline{\mathrm{o}}$ e $10^{\circ} \mathrm{o}$ dias, notou-se maior peso dos intestinos dos perus inoculados com Salmonella Enteritidis na casca. Aos 28 dias de idade, o maior peso de intestino foi verificado em perus inoculados com Salmonella Enteritidis na água de bebida.

Pelo exame biométrico do intestino, o maior peso de intestino ocorreu aos 10 dias de idade, como descrito por Sell et al. (1991) e Uni et al. (1999). Sabe-se que o peso do intestino aumenta paralelamente ao peso corporal até a eclosão e passa a aumentar mais rapidamente que a massa corporal após o nascimento. Esse rápido crescimento relativo do intestino delgado é máximo em 6 a 8 dias para perus (Sell et al., 1991).

Perus inoculados com Salmonella Enteritidis apresentaram peso relativo de intestino maior com 1,10 e 28 dias de idade. Esses dados estão de acordo com os encontrados por Andrade (2005), que encontrou valores maiores com 1, 14 e 21 dias em frangos de corte desafiados por esse mesmo patógeno. Esse maior peso relativo pode ser explicado pelo estímulo antigênico da Salmonella

Tabela 1 - Resultados da pesquisa de Salmonella Enteritidis em mecônio e suabe cloacal de perus inoculados na casca no início da incubação e água de bebida com 1, 15 e 28 dias de idade

\begin{tabular}{|c|c|c|c|c|}
\hline \multirow[t]{2}{*}{ Idade (dias) } & \multicolumn{2}{|c|}{ Inoculado - Casca } & \multicolumn{2}{|c|}{ Inoculado - Água bebida } \\
\hline & $\begin{array}{c}\text { Amostras positivas/ } \\
\text { processadas }\end{array}$ & $\%$ & $\begin{array}{l}\text { Amostras positivas/ } \\
\text { processadas }\end{array}$ & $\%$ \\
\hline 1 & $6 / 57$ & $10,5 \%$ & - & - \\
\hline 15 & $14 / 36$ & $38,9 \%$ & $7 / 26$ & $26,9 \%$ \\
\hline 28 & $11 / 27$ & $40,7 \%$ & $3 / 18$ & $16,7 \%$ \\
\hline
\end{tabular}

* Letras diferentes na mesma linha indicam diferença $(\mathrm{P}<0,05)$ pelo teste $\chi^{2}$. 
Tabela 2 - Isolamento de Salmonella Enteritidis em conteúdo cecal de perus oriundos de inoculação na casca e água de bebida com 1, 10, 20 e 28 dias de idade

\begin{tabular}{lcccc}
\hline Via de inoculação & \multicolumn{4}{c}{ Idade (dias) } \\
\cline { 2 - 5 } & 1 & 10 & 20 & 28 \\
\hline & $\mathrm{n}$ & & & \\
Casca & $4 / 4$ & $1 / 4$ & $0 / 4$ & $2 / 4$ \\
Água & - & $3 / 4$ & $2 / 4$ & $2 / 4$ \\
Total positivo & $4 / 4$ & $4 / 8$ & $2 / 8$ & $4 / 8$ \\
\hline
\end{tabular}

Enteritidis no intestino no primeiro dia de idade (Andrade, 2005). De acordo com Noy \& Sklan (1997), a presença de qualquer material exógeno no trato gastrintestinal é suficiente para estimular a atividade e o desenvolvimento da mucosa intestinal, os quais promovem redução ou melhora na capacidade digestiva e absortiva. Por outro lado, pela análise do comprimento do intestino, não foram observadas diferenças $(\mathrm{P}>0,05)$ entre os grupos. Estes dados poderiam ser mais bem explorados se a pesagem tivesse sido realizada por segmentos (duodeno, jejuno e íleo), como apresentado em estudos anteriores, conduzidos por Sell et al. (1991), Applegate et al. (2005) e Poturri et al. (2005).
Ao se compararem os resultados dos exames histomorfométricos (Tabela 4) dos segmentos do intestino avaliados, as alturas das vilosidades do duodeno e do jejuno aumentaram rapidamente com a idade e esses segmentos cresceram paralelo e mais rapidamente que o íleo, como descrito por Uni et al. (1999). Aos 10 dias, as aves pertencentes ao grupo controle apresentaram significativamente $(\mathrm{P}<0,05)$ menor altura de vilo do duodeno em relação àquelas que receberam os patógenos, sendo que os vilos do jejuno das aves do mesmo grupo apresentaram maior $(\mathrm{P}<0,05)$ altura.

A inoculação com Salmonella Enteritidis afetou e promoveu maior altura de vilosidade até 10 dias de idade, sendo superado pelo grupo controle aos 20 dias e igualando-se aos 28 dias no grupo inoculado na casca.

A profundidade de cripta em todos os segmentos se manteve maior nos grupos inoculados com o patógeno, exceto no $10^{\mathrm{o}}$ dia. Não houve diferença $(\mathrm{P}>0,05)$ entre os grupos. Os dados deste trabalho sugerem que esses aumentos foram diretamente relacionados à renovação das células epiteliais (turnover) durante a infecção e indicam resposta compensatória das células aos efeitos da Salmonella Enteritidis. Segundo Pluske et al. (1997), o

Tabela 3 - Peso relativo (g/100 g de peso vivo) do intestino, comprimento do intestino de perus com 1, dez, 20 e 28 dias de idade

\begin{tabular}{|c|c|c|c|c|c|c|c|c|}
\hline \multirow[t]{2}{*}{ Via de inoculação } & \multicolumn{2}{|c|}{1 dia } & \multicolumn{2}{|c|}{10 dias } & \multicolumn{2}{|c|}{20 dias } & \multicolumn{2}{|c|}{28 dias } \\
\hline & $\begin{array}{l}\text { Peso } \\
\text { inicial }\end{array}$ & $\begin{array}{l}\text { Comprimento } \\
\text { do intestino }\end{array}$ & $\begin{array}{l}\text { Peso } \\
\text { inicial }\end{array}$ & $\begin{array}{l}\text { Comprimento } \\
\text { do intestino }\end{array}$ & $\begin{array}{l}\text { Peso } \\
\text { inicial }\end{array}$ & $\begin{array}{l}\text { Comprimento } \\
\text { do intestino }\end{array}$ & $\begin{array}{l}\text { Peso } \\
\text { inicial }\end{array}$ & $\begin{array}{r}\text { Comprimento } \\
\text { do intestino }\end{array}$ \\
\hline Casca & $5,3 \mathrm{~A}$ & 40,9 & $10,2 \mathrm{~A}$ & 79,7 & 6,5 & 93,5 & $4,0 \mathrm{~B}$ & 110,7 \\
\hline Água & - & - & $8,0 \mathrm{~B}$ & 80,9 & 5,7 & 105,3 & $4,6 \mathrm{~A}$ & 116,5 \\
\hline
\end{tabular}

* Letras diferentes na mesma coluna indicam diferença $(\mathrm{P}<0,05)$ pelo teste Tukey a $5 \%$.

Tabela 4 - Alturas dos vilos e profundidade de cripta do duodeno $(\mu \mathrm{m})$, jejuno $(\mu \mathrm{m})$ e do íleo $(\mu \mathrm{m})$ de perus de corte de 1 a 28 dias de idade

\begin{tabular}{|c|c|c|c|c|c|c|c|c|}
\hline \multirow[t]{3}{*}{ Vias de inoculação } & \multicolumn{8}{|c|}{ Duodeno } \\
\hline & \multicolumn{4}{|c|}{ Altura de vilos } & \multicolumn{4}{|c|}{ Profundidade de cripta } \\
\hline & 1 dia & 10 dias & 20 dias & 28 dias & 1 dia & 10 dias & 20 dias & 28 dias \\
\hline Controle & $494,7 B^{*}$ & $804,8 \mathrm{C}$ & $1133,6 \mathrm{~A}$ & $1143,7 \mathrm{~B}$ & $80,3 \mathrm{~B}$ & $140,5 B$ & $147,8 \mathrm{~B}$ & $120,2 \mathrm{C}$ \\
\hline Casca & $634,8 \mathrm{~A}$ & $860,3 \mathrm{~B}$ & $831,9 \mathrm{C}$ & $1149,6 \mathrm{~A}$ & $128,6 \mathrm{~A}$ & $152,4 \mathrm{~A}$ & $218,7 \mathrm{~A}$ & $175,9 \mathrm{~B}$ \\
\hline \multirow[t]{2}{*}{ Água } & - & $966,1 \mathrm{~A}$ & 955,9B & $945,7 \mathrm{~B}$ & - & $146,8 \mathrm{~A}$ & $230,9 \mathrm{~A}$ & $195,6 \mathrm{~A}$ \\
\hline & \multicolumn{8}{|c|}{ Jejuno } \\
\hline Controle & $414,1 \mathrm{~A}$ & $708,3 \mathrm{~A}$ & $-* *$ & $957,8 \mathrm{~A}$ & $84,7 \mathrm{~B}$ & 117,6 & $-* *$ & $178,4 \mathrm{~B}$ \\
\hline Casca & $360,1 \mathrm{~B}$ & $533,5 \mathrm{~B}$ & $676,6 \mathrm{~A}$ & $504,2 \mathrm{C}$ & $109,7 \mathrm{~A}$ & 137,4 & $261,2 \mathrm{~A}$ & $479,3 \mathrm{~A}$ \\
\hline \multirow[t]{2}{*}{ Água } & - & $448,6 \mathrm{C}$ & $382,2 \mathrm{~B}$ & $676,3 \mathrm{~B}$ & - & 118,6 & 199,2B & $141,8 \mathrm{~B}$ \\
\hline & \multicolumn{8}{|c|}{ Íleo } \\
\hline Controle & 349,1 & $561,5 \mathrm{~B}$ & $612,8 \mathrm{~A}$ & 799,1A & $130,7 \mathrm{~B}$ & - & $162,6 \mathrm{~B}$ & $224,6 B$ \\
\hline Casca & 311,7 & $691,2 \mathrm{~A}$ & $351,8 \mathrm{~B}$ & $505,4 \mathrm{C}$ & $159,9 \mathrm{~A}$ & - & $214,1 \mathrm{~B}$ & $351,6 \mathrm{~A}$ \\
\hline Água & - & $358,6 \mathrm{C}$ & $605,6 \mathrm{~A}$ & $683,4 \mathrm{~B}$ & - & - & $411,3 \mathrm{~A}$ & $230,1 \mathrm{~B}$ \\
\hline
\end{tabular}

* Letras diferentes na mesma coluna diferem estatisticamente pelo teste Tukey a 5\%.

** 20 o dia, o excesso de artefatos impossibilitou a leitura do tratamento controle. 
maior valor de profundidade de cripta indica maior atividade proliferativa celular. Loddi et al. (2004) também mostraram que, se os vilos reduzem seu tamanho em decorrência do aumento da perda celular, como consequência ocorre aumento na produção de células da cripta e na profundidade de cripta.

A inoculação de Salmonella Enteritidis influenciou $(\mathrm{P}<0,05)$ o peso médio de perus ao $1^{\underline{0}}, 10^{\underline{0}}$ e 20 을 dias de idade (Tabela 5).

O menor peso $(\mathrm{P}<0,05)$ ao nascimento foi observado em perus oriundos da inoculação da casca, o que sugere algum efeito do patógeno no período anterior ou durante a eclosão. O peso médio observado ao nascimento $(60,07$ a 63,95 g) foi semelhante aos dados de estudos anteriores de Sell et al. (1991), que encontraram pesos de 64,8 6,9 9 g, e por Applegate et al. (2005), que observaram variação de 62,19 a 65,63 g no peso corporal de perus à eclosão.

Observou-se menor ganho de peso médio ao $1^{\circ}, 10^{\circ} \mathrm{o} \mathrm{e}$ $20^{\circ}$ dias de idade das aves que sofreram desafios pela bactéria na casca, fato que pode ser atribuído à presença do agente infeccioso no trato gastrintestinal. Esses resultados estão aliados aos exames histomorfométricos do duodeno no $1^{\underline{0}}$ e 20 o dias, que evidenciaram menores $(\mathrm{P}<0,05)$ valores para as alturas dos vilos e maiores para profundidade de cripta. Provavelmente a presença de Salmonella Enteritidis comprometeu a digestão e a absorção adequadas dos nutrientes. Os perus inoculados sofreram perdas de peso médio aproximado de 6,07; 26,49 e $20,50 \%$ com 1, 10 e 20 dias, respectivamente. Essa redução no ganho de peso também foi observada em frangos de corte por Gorham et al. (1994), Dhillon et al. (1999) e Andrade (2005), que encontraram aves com ganho de peso inferior em inoculações com Salmonella Enteritidis.

Com 10, 20 e 28 dias, pode-se afirmar que os pesos médios foram abaixo das recomendações da linhagem, exceto no grupo controle. É possível verificar variações mais acentuadas entre lotes sexados, entretanto o peso médio recomendado é de $210 \mathrm{~g}$ aos 10 dias, 540 a 620 g com 20 dias e 950 a 1.130 g com 28 dias (BUT, 2006b).

Houve diferença significativa na conversão alimentar $(\mathrm{P}<0,05)$ entre os grupos aos dez dias de idade (Tabela 6),

Tabela 5 - Peso médio de perus de corte ao $1^{\circ}$, $10^{\circ} \underline{0} 20^{\circ}$ e $28^{\circ}$ dia de idade

\begin{tabular}{lcccc}
\hline Vias de inoculação & 1 o dia & $10^{\underline{o}}$ dia & 20 o dia & $28^{\underline{o}}$ dia \\
\hline Controle & $63,95 \mathrm{~A}$ & $210,15 \mathrm{~A}$ & $548,98 \mathrm{~A}$ & 977,47 \\
Casca & $60,07 \mathrm{~B}$ & $154,49 \mathrm{~B}$ & $438,64 \mathrm{~B}$ & 811,67 \\
Água & $62,41 \mathrm{~A}$ & $187,14 \mathrm{~A}$ & $472,70 \mathrm{AB}$ & 927,62 \\
CV $(\%)$ & 3,11 & 12,65 & 12,69 & 16,98 \\
\hline
\end{tabular}

Letras diferentes na mesma coluna diferem estatisticamente pelo teste Tukey a 5\%.
Tabela 6 - Conversão alimentar de perus de corte ao 10ํㅡ, $20^{\circ}$ e e 280 dia de idade

\begin{tabular}{lccc}
\hline Vias de inoculação & $10^{\circ}$ dia & $20^{\circ}$ dia & $28^{\circ}$ dia \\
\hline Controle & $1,12 \mathrm{~A}$ & 1,55 & 1,74 \\
Casca & $1,46 \mathrm{~B}$ & 1,55 & 2,16 \\
Água & $1,26 \mathrm{~A}$ & 2,14 & 1,46 \\
\hline Letras diferentes namesma coluna diferem estatisticamente pelo teste
\end{tabular}

de modo que, no grupo submetido a inoculação na casca do ovo, a conversão alimentar foi pior em relação ao tratamento que recebeu o patógeno na água e ao grupo controle. No entanto, a recomendação para a linhagem em estudo é de 0,93 a 0,98 na primeira semana; 1,22 a 1,26 na segunda semana; 1,35 a 1,42 da terceira semana e 1,44 a 1,55 na quarta semana (BUT, 2006b).

A pior conversão aos 10 dias de vida pode ser atribuída às alterações morfométricas das células epiteliais do intestino causadas pela Salmonella Enteritidis no duodeno e jejuno, locais onde ocorre maior nível de absorção.

\section{Conclusões}

A contaminação da casca do ovo antes da incubação aumenta a incidência de infecção ao nascimento. A frequência de isolamento de Salmonella Enteritidis persiste até 28 dias de idade. A patogênese da infecção envolve a colonização intestinal. Por outro lado, a contaminação de perus pela água, que simularia a contaminação no galpão de criação, gera aves infectadas, porém a infecção reduz com o avançar da idade. Na criação de perus, infecções por Salmonella causam redução de desempenho, com menor peso corporal, maior conversão alimentar e menor peso de intestino. As aves desafiadas apresentam desempenho inferior aos padrões da linhagem. Salmonella Enteritidis afeta a integridade das estruturas das células intestinais, alterando os índices histomorfométricos.

\section{Agradecimentos}

À Brasil Foods SA, pelo apoio técnico e fornecimento da matéria-prima; ao CNPq, pelo financiamento e bolsa; e à Dra. Eliana Falavina dos Reis (FIOCRUZ), pela sorotipagem.

\section{Referências}

ANDRADE, M.A.; STRINGHINI, J.H.; MESQUITA, A.J. et al. Aspectos clínicos e anatomohistopatológicos de pintos de corte oriundos de ovos inoculados experimentalmente com Salmonella Enteritidis fagotipo 4. Ciência Animal Brasileira, v.10, n.3, p.909-917, 2009.

APPLEGATE, T.J.; KARCHER, D.M.; LILBURN, M.S. Comparative development of the small intestine in the turkey poult and Pekin ducking. Poultry Science, v.84, n.3, p.426-431, 2005. 
BACK, A. Manual de doenças das aves. Cascavel: Integração, 2002. 246p.

BACK, A. Ongoing turkey diseases in Brazil. In: INTERNATIONAL SYMPOSIUM ON TURKEY DISEASES, 7., 2008, Berlim, Anais... Berlim: German Branch of World Veterinary Poultry Association, 2008. p.24.

BAILEY, J.S.; COX, N.A.; BERRANG, M.E. Hatchery-acquired Salmonellae in broiler chicks. Poultry Science, v.73, n.9, p.1153-1157, 1994.

BERTHELOT-HÉRAULT, F.; MOMPART, F.; ZYGMUNT, M.S. et al. Antibody responses in the serum and gut of chickens lines differing in cecal carriage of Salmonella Enteritidis. Veterinary Immunology and Immunopathology, v.96, n.1, p.43-52, 2003.

BRASIL. Ministério da Agricultura e do Abastecimento. Secretaria Nacional da Defesa Agropecuária. Departamento Nacional de Defesa Animal. Coordenação Geral de Laboratório Animal. Métodos de análises microbiológicas para alimentos. Brasília: MAPA, 2003. 226p.

BRITISH UNITED TURKEYS - BUT. BUT performance goals. 5.ed. Inglaterra: British United Turkeys, 2006a. 6p.

BRITISH UNITED TURKEYS - BUT. BUT Big9 commercial performance goals. 5.ed. Inglaterra: British United Turkeys, 2006b. 7.p.

CHARLES, S.D.; HUSSAIN I.; CHOI, C. et al. Adjuvanted subunit vaccines for the control of Salmonella Enteritidis infection in turkeys. American Journal of Veterinary Research, v.55, n.5, p.636-642, 1994.

COX, N.A.; BAILEY, J.S.; STERN, N.J. Effectiveness of an undefined mucosal competitive exclusion treatment to control Salmonella in turkeys during brooding. Journal of Applied Poultry Research, v.10, n.2, p.319-322, 2001.

DHILLON, A.N.; ALISANTOSA, B.N.; SHIVAPRASAD, H.L. et al. Pathogenicity of Salmonella Enteritidis Phage Types 4, 8 and 23 in broiler chicks. Avian Diseases, v.43, n.3, p.506-515, 1999.

DHILLON, A.S.; SHIVAPRASAD, H.L.; ALISANTOSA, B.N. et al. Pathogenicity of environmental origin Salmonellas in specific pathogen-free chicks. Poultry Science, v.80, n.9, p.11323-1138, 2001.

EUCLIDES, R.F. Manual de utilização do SAEG (Sistema para Análise Estatística e Genética). Viçosa, MG: Universidade Federal de Viçosa, 1983. 59p.

GEORGiA POULTRY LABORATORY - GPL. Monitoring and detection of Salmonella in poultry and poultry environments. Oakwood: Georgia Poultry Laboratory, 1997. 293p. [Workshop].

GORHAM, S.L.; KADAVIL, K.; VAUGAHAN, E. et al. Gross and microscopic lesions in young chickens experimentally with
Salmonella enteritidis. Avian Diseases, v.38, n.3, p.816-821, 1994.

HOOVER, N.J.; KENNEY, P.B.; AMICK, J.D. et al. Preharvest sources of Salmonella colonization in turkey production. Poultry Science, v.76, n.9, p.1232-1238, 1997.

KRÜGER, A.; REDMANN, T.; KRAJEWSKI, V. Field investigations on the efficacy of a live vaccine of Salmonella Enteritidis in meat turkeys. In: INTERNATIONAL SYMPOSIUM ON TURKEY DISEASES, 7., 2008, Berlim, Anais... Berlim: German Branch of World Veterinary Poultry Association, 2008. p.60.

LODDI, M.M.; MORAES, V.M.B.; NAKAGHI, L.S.O et al. Uso de probióticos e prebióticos em dietas iniciais de frango de corte sobre densidade intestinal. Avicultura Industrial, n.1, p.110-112, 2004.

LUNA, L.G. Manual of histologic staining methods of the armed forces institute of pathology. 3.ed. New York: McGraw-Hill, 1968. 258p.

NOY, Y.; GEYRA, A.; SKLAN, D. The effect of early feeding on growth and small intestinal development in posthatch poult. Poultry Science, v.80, n.7, p.912-919, 2001.

NOY, Y.; SKLAN, D. Poshatch development in poultry. Journal of Applied Poultry Research, v.6, n.1, p.344-354, 1997.

PLUSKE, J.R.; HAMPSON, D.J.; WILLIAMS, I.H. Factors influencing the structure and function of the small intestine in the weaned pig: a review. Liverstock Production Science, v.51, n.1-3, p. 215-236, 1997.

POTTURI, P.V.L.; PATTERSON, J.A.; APPLEGATE, T.J. Effects of delayed placement on intestinal characteristics in turkey poults. Poultry Science, v.84, n.5, p.816-824, 2005.

ROCHA, P.T.; MESQUITA, A.J.; ANDRADE, M.A. et al. Salmonella spp. em forros de caixa de transporte e órgãos de pintos de um dia. Arquivos Brasileiros de Medicina Veterinária, v.55, n.6, p.672-676, 2003.

SAMPAIO, I.B.M. Estatística aplicada à experimentação animal. Belo Horizonte: Fundação de Ensino e Pesquisa em Medicina Veterinária e Zootecnia, 2002. 221p.

SELL, J.L.; ANGEL, C.R.; PIQUER, J. et al. Developmental patterns of selected characteristics of the gastrointestinal tract of young turkeys. Poultry Science, v.70, n.10, p.1200-1205, 1991.

SILVA, E.N.; DUARTE, A. Salmonella Enteritidis em aves: retrospectiva no Brasil. Revista Brasileira de Ciência Avícola, v.4, n.2, p.1-16, 2002.

UNI, Z.; GANOT, S.; SKLAND, D. Posthatch development of mucosal function in the broiler small intestine. Poultry Science, v.77, p.75-82, 1998.

UNI, Z.; NOY, Y.; SKLAN, D. Poshatch development of small intestinal function in the poult. Poultry Science, v.78, n.2, p.215-222, 1999. 